\title{
Effect of Stress Generated by Occlusal Cyclic Force on Class I Bulk-Fill Composite Restoration Microleakage
}

\author{
Apirat Ritthiti $^{1}$ Vanthana Sattabanasuk ${ }^{2}$ Kavin Karunratanakul ${ }^{3}$ Pisol Senawongse ${ }^{2}$
}

${ }^{1}$ Department of Conservative Dentistry, Faculty of Dentistry, Srinakharinwirot University, Bangkok, Thailand

2 Department of Operative Dentistry and Endodontic, Faculty of Dentistry, Mahidol University, Bangkok, Thailand

${ }^{3}$ Biomedical Engineering Research Unit, National Metal and Materials Technology Center, Bangkok, Thailand

\author{
Address for correspondence Pisol Senawongse, PhD, Department of \\ Operative Dentistry and Endodontics, Faculty of Dentistry, Mahidol \\ University, 6 Yothi Street, Rajthevi, Bangkok 10400, Thailand \\ (e-mail: pisol.sen@mahidol.ac.th).
}

Eur J Dent 2022;16:307-314.

\begin{abstract}
Keywords

- composite restoration

- cyclic loading

- finite element

- microleakage

- occlusal force

- stress

Objective This study aimed to evaluate the effects of different types and restorative techniques of Class I composite restorations with a single loading force on stress distribution and cyclic loading force on microleakage formation.

Materials and Methods Class I cavities were prepared in premolars with $4 \mathrm{~mm}$ depth and divided into six groups of different restorations with: (1) Filtek Z250; (2) a 3-mmthick layer of Filtek Bulk Fill Flowable Restoration and covered with Z250; (3) a 1.5-mmthick layer of flowable composite and covered with Z250; (4) lining all cavity with flowable composite and restored with Z250; (5) Filtek Bulk Fill Posterior Restoration; and (6) lining all cavity with flowable composite and restored with bulk-fill composite. The specimens with and without cyclic occlusal loading were subjected to microleakage observation. In addition, six different models of Class I restorations corresponding to the microleakage study were generated. Finite element analysis (FEA) was used to identify the stress distribution under a single loading force.

Statistical Analysis Data were statistically analyzed by two-way analysis of variance and multiple comparison. The significance level set at 0.05 .

Results Cavity lining or restoration with flowable composite underneath conventional composite reduced stress on composite resin based on FEA (groups 2 and 3). The cyclic stress on composite increased microleakage. Restoration with flowable composite underneath conventional composite reduced the microleakage in Class I restoration (groups 2, 3, and 4).

Conclusion The most effective cavity lining with a flowable composite underneath conventional composite restoration was stress reduction under loading force resulting in microleakage reduction.
\end{abstract}

\section{Introduction}

Posterior composite restorations have become widely used in dentistry because of their high success rate and conservation-related properties. Therefore, a decrease in the success rate after 5 years has been reported to be caused by secondary caries. Otherwise, marginal fracture and bulk fracture could necessitate the replacement of posterior composite restorations in long-term observation. ${ }^{1-3}$ published online October 21, 2021
DOI https://doi.org/ 10.1055/s-0041-1735433. ISSN 1305-7456.
(C) 2021. The Author(s).

This is an open access article published by Thieme under the terms of the Creative Commons Attribution License, permitting unrestricted use, distribution, and reproduction so long as the original work is properly cited. (https://creativecommons.org/licenses/by/4.0/)

Thieme Medical and Scientific Publishers Pvt. Ltd., A-12, 2nd Floor, Sector 2, Noida-201301 UP, India 
Clinically, posterior teeth are subjected to occlusal force with cyclic loading during mastication. Restorative materials are subjected to such cyclic stress and undergo material fatigue. This fatigue may cause defects that ultimately lead to a fracture in the materials at a stress level lower than that required for a single load application. ${ }^{4-7}$ A recent study reported the effect of a single stress of $50 \mathrm{~N}$ loading on a Class I composite restoration from a two-dimensional model of finite element analysis. It produced the highest stress of $62.75 \mathrm{MPa}$ at the enamel cavosurface. The stresses at the adhesive layer and resin composite were 54.63 and 42.11 $\mathrm{MPa}$, respectively. Additionally, the use of the flowable composite lining reduced the stress. ${ }^{8}$ With the application of cyclic stress, this $50 \mathrm{~N}$ stress may induce failure at the tooth/resin composite interface. ${ }^{9}$ Additionally, different resin composites with different compositions showed different fatigue strengths for the different materials. ${ }^{10}$

The currently developed composite resin called "bulk-fill composite resin" is claimed to have the potential of bulkfilling down to a depth of $4 \mathrm{~mm} .{ }^{11-13}$ This material also has the advantage of shrinkage stress reduction ${ }^{14}$ and low cuspal deflection because of low shrinkage stress. ${ }^{15}$ The bulk-fill composite resin can be classified into two groups regarding the viscosity: flowable or low viscosity composite and regular or high viscosity composite. The term "packable composite" is used with the relatively high viscosity composite. As mentioned by Leprince and coworkers, the use of bulk-fill composite resin can reduce the working time and lead clinicians to feel comfortable. Therefore, the disadvantage of this material is its poor mechanical properties compared with those of conventional composites. It is not appropriate to use for restoration in areas with high occlusal loads. ${ }^{16}$

Additionally, the trends of restorations with resin composite lined with a flowable composite are growing. ${ }^{17}$ The manufacturer recommends restoring the cavity deep, down to $4 \mathrm{~mm}$, with one layer of bulk-fill flowable composite. Therefore, the flowable composite should be covered with a regular composite because of its low surface hardness and low elastic modulus. ${ }^{18-20}$ Filling the cavity with a thick layer of flowable composite underneath the regular composite is also a questionable approach with respect to the ability and durability under occlusal loading.

To date, there are no publications in which fatigue testing was performed in combination with a microleakage test. This combination may stimulate the clinical condition in which a restored tooth is fatigued, resulting in microleakage and ultimately restoration failure. The null hypothesis of this study was that there were no significant differences in the microleakage of Class I restorations with different composite types with different restorative techniques under cyclic occlusal force.

\section{Materials and Methods}

This study was performed by using protocols approved by the Faculty of Dentistry/Faculty of Pharmacy, Mahidol University Institutional Review Board.

\section{Finite Element Analysis}

A three-dimensional image of a maxillary premolar tooth with a Class I preparation was taken by using a micro-CT (microcomputed tomography) scan (Skyscan 1173, Bruker, Kontich, Belgium). The micro-CT was set with a nominal voltage of $100 \mathrm{kV}$, current strength of $100 \mathrm{~mm}$, and voxel size of $7.8 \mathrm{~mm}$. The CT images were stored in DICOM format. Mimics software (Solidworks, Dassault Systems SolidWorks Corporation, Waltham, Massachusetts, United States) and power shape (Autodesk Inc, San Rafael, California, United States) were used to establish the tooth model with a Class I cavity for finite element analysis. The dimensions of the model are demonstrated in - Fig. $\mathbf{1}$.

The model consisted of enamel, dentin, a hybrid layer in dentin (assigned thickness $=1 \mu \mathrm{m}$ ), an adhesive layer (assigned thickness $=10 \mu \mathrm{m}$ ), and various methods of resin composite restoration. Six models were established according to the restorative techniques: Model 1: the cavity was restored with Filtek Z250 for a depth of $4 \mathrm{~mm}$; Model 2: the bottom of the cavity was restored with Filtek Bulk Fill Flowable Restoration for $3 \mathrm{~mm}$ and covered occlusally with Filtek Z250 for $1 \mathrm{~mm}$; Model 3: the bottom of the cavity was restored with Filtek Bulk Fill Flowable Restoration for $1.5 \mathrm{~mm}$ and covered occlusally with Filtek Z250 for $2.5 \mathrm{~mm}$; Model 4: the prepared surfaces of the cavity were lined with $0.5 \mathrm{~mm}$ thick of Filtek Bulk Fill Flowable Restoration and the remaining cavity was restored with Filtek Z250; Model 5: the cavity was restored with Filtek Bulk Fill Posterior Restoration for a depth of $4 \mathrm{~mm}$; and Model 6: the prepared surfaces of cavity were lined with a 0.5 -mm-thick layer of Filtek Bulk Filtek Flowable Restoration and of remaining cavity was restored with Filtek Bulk Fill Posterior Restoration. Element types were tetrahedral with 563,365 elements and 840,399 nodes for Model 1; 584,804 elementsand 872,451 nodes for Model 2; 578,151elements and 871,546 nodes for Model 3; 570,659 elements and 871,546 nodes for Model 3; 570,659 elements and 870,439 nodes for Model 5; and 582,273 elements and 868,276 nodes for Model 6 .

The tooth model was then imported into finite element analysis software (ANSYS Workbench, ANSYS Inc, Canonsburg, Pennsylvania, United States). To calculate the FEA,

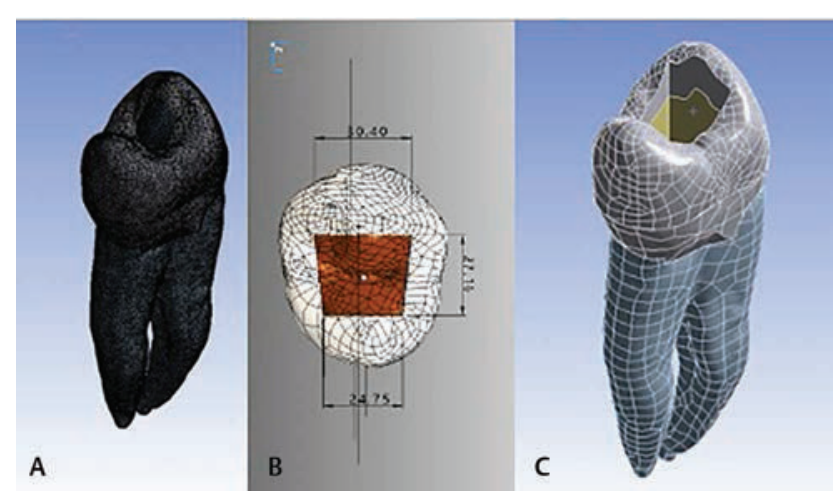

Fig. 1 Tooth model with Class I cavity. (A) Three-dimensional tooth model, (B) dimensions of occlusal cavity are $30.40 \times 27.16 \times 24.74$ $\times 27.16 \mathrm{~mm}$, and $(C)$ depth of the cavity is $40 \mathrm{~mm}$ from the central groove. 
Poisson's ratio and the elastic modulus of all materials were

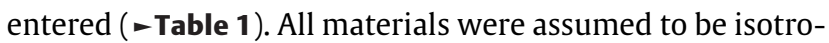
pic and linearly elastic.

For the modulus of Filtek Z250, Filtek Bulk Fill Posterior Restorative, Filtek Bulk Fill Flowable Restorative, Single Bond Universal, and Fuji II LC, 10 extracted sound human premolars were used in this study. A Class I square butt-joint cavity was prepared with a water-cooled high-speed handpiece and a cylindrical diamond bur (FG 210/6, Intensive, Montagnola, Switzerland) by extending the cavity from the buccal cusp to the lingual cusp with a 2-mm buccolingual width and extending from the mesial to the distal pit with a $2.5-\mathrm{mm}$ mesiodistal length. All cavities were prepared with a depth of $5 \mathrm{~mm}$. The cavity was lined with a glass-ionomer cement (Fuji II LC) until achieving a depth of $3.5 \mathrm{~mm}$ from the cavity margin. The cavity was then finished with the diamond bur to obtain the cavity with dimension approximate of $4.0 \times 2.5 \times 3 \mathrm{~mm}$ (depth $\times$ width $\times$ length). The dimension of cavity was verified by the measurement with a periodontal probe by another investigator to ensure accuracy. The prepared cavities were divided into two groups of five teeth for restoration with (1) bonding with Single Bond Universal, Restoration with Filtek Bulk Fill Flowable Restoration for $3 \mathrm{~mm}$ and FiltekZ250 for $1 \mathrm{~mm}$ as shown in Model 2, and (2) bonding with Single Bond Universal, lining with a $0.5-\mathrm{mm}$ thick layer of Filtek Bulk Fill Flowable Restoration and filling with Filtek Bulk Fill Posterior Restoration as shown in Model 6. The specimens were cured for 40 seconds incrementally with a light-emitting diode (LED) curing unit (Bluephase, Ivoclar Vivadent, Schaan, Liechtenstein) with the intensity of more than $1,100 \mathrm{~mW} / \mathrm{cm}$ measured with a radiometer (Bluephase Meter, Ivoclar Vivadent, Schaan, Liechtenstein). The specimens of each group were sectioned buccolingually with a low-speed cutting machine (Isomet, Buehler, Lake Bluff, Illinois, United States) with a diamond blade (Isocut, Buehler, Lake Bluff, Illinois, United States). The cut specimens were then embedded in epoxy resin (Epon 815, Nissin, Tokyo, Japan) in polyvinylchloride rings. After the epoxy resin was set, the embedded specimens were polished

Table 1 Elastic modulus and Poisson's ratio of enamel, dentin, the hybrid layer, adhesive resin, flowable composites, and composite resin

\begin{tabular}{|l|l|l|}
\hline Structures & $\begin{array}{l}\text { Poisson's } \\
\text { ratio }\end{array}$ & $\begin{array}{l}\text { Elastic modulus } \\
\text { (GPa) }\end{array}$ \\
\hline Enamel & $0.25^{21}$ & $88.5 \pm 5.43$ \\
\hline Dentin & $0.30^{21}$ & $25.63 \pm 3.23$ \\
\hline Hybrid layer & $0.30^{22}$ & $12.75 \pm 1.47$ \\
\hline Filtek Z250 & $0.25^{24}$ & $20.88 \pm 1.26$ \\
\hline $\begin{array}{l}\text { Filtek Bulk Fill Posterior } \\
\text { Restorative }\end{array}$ & $0.25^{24}$ & $11.60 \pm 0.59$ \\
\hline $\begin{array}{l}\text { Filtek Bulk Fill Flowable } \\
\text { Restorative }\end{array}$ & $0.28^{23}$ & $5.26 \pm 0.05$ \\
\hline Single Bond Universal & $0.35^{24}$ & $1.26 \pm 0.51$ \\
\hline Fuji II LC (as pulp) & $0.35^{23}$ & $8.23 \pm 2.10$ \\
\hline
\end{tabular}

with wet silicon carbide paper of decreasing abrasiveness (600; 800; 1,000; and 1,200 grit) and polished with diamond paste down to a grain size of $0.25 \mu \mathrm{m}$. The polished specimens were attached to a nanohardness testing system (NHT, CSM Instrument, Peseux, Switzerland) to measure the elastic modulus with 5,000 mgf loading on dentin, the adhesive and the resin composite and with 1,000 mgf loading on hybrid layers in a closed environment with dry conditions. Poisson's ratios used for the elastic modulus determination were included from previous studies. ${ }^{21-24}$ Five indentations were performed in each substrate for each specimen. Moduli of elasticity (Gigapascal, GPa) were calculated from the attached computer.

The models were subjected to an occlusal load of $50 \mathrm{~N}^{25,26}$ The load was applied at the reference point on the occlusal surface, parallel to the long axis. The representative finite element analysis of three-dimensional Model 1 of each structure after receiving a $50 \mathrm{~N}$ occlusal load onto the composite resin is shown in - Fig. 2. The Von Mises stress (MPa) and deformation ( $\mathrm{mm}$ ) from each structure were obtained from all models. The pictures from the finite element analysis are presented in - Fig. $\mathbf{3}$.

\section{Microleakage Testing with Microcomputed Tomography}

Thirty maxillary second premolars of similar size without carious lesions or restorations extracted by orthodontic methods and kept in $0.1 \%$ thymol solution at $4^{\circ} \mathrm{C}$ were used within 6 months. A class I cavity was prepared with the high-speed cylindrical diamond bur by extending the cavity, following tooth preparation for nanoindentation testing. A new bur was used for every cavity preparation. Then, the cavities were divided into six groups of five teeth and restored as six models in the finite element analysis models. Before restorations, an adhesive (Single Bond Universal Adhesive) was applied to the cavities in selfetch mode following the manufacturer's instructions. Then, the specimens of Groups 1 to 6 were restored as mention in Model 1 to Model 6, sequently. Each increment of material was cured with the LED curing unit for $40 \mathrm{sec}-$ onds. The materials used for restoration are demonstrated in -Table 2. All specimens were surface polished with three sequences of silicone-impregnated polishing devices (Astropol F/P/HP, Ivoclar Vivadent, Schaan, Liechtenstein) using a slow-speed handpiece running at $12,000 \mathrm{rpm}$ under dry conditions immediately after polymerization. The restored teeth were kept in distilled water at $37^{\circ} \mathrm{C}$ for 24 hours. Then, microleakage testing with micro-CT was performed.

After 24 hours of storage, the tooth surface of the specimen was coated with two layers of nail varnish leaving $1 \mathrm{~mm}$ between the interface of the tooth and the restoration. The coated specimens were immersed in $50 \%$ ammoniacal $\mathrm{AgNO}_{3}$ solution for 24 hours as a tracer, which developed in X-ray developing solution for 15 minutes and fixed for 2 minutes. Then, the specimens were subjected to micro-CT scanning. The micro-CT was set with a nominal voltage of $100 \mathrm{kV}$, current strength of $100 \mu \mathrm{A}$, and voxel size of $7.8 \mu \mathrm{m}$. Micro-CT images were used to investigate microleakage 

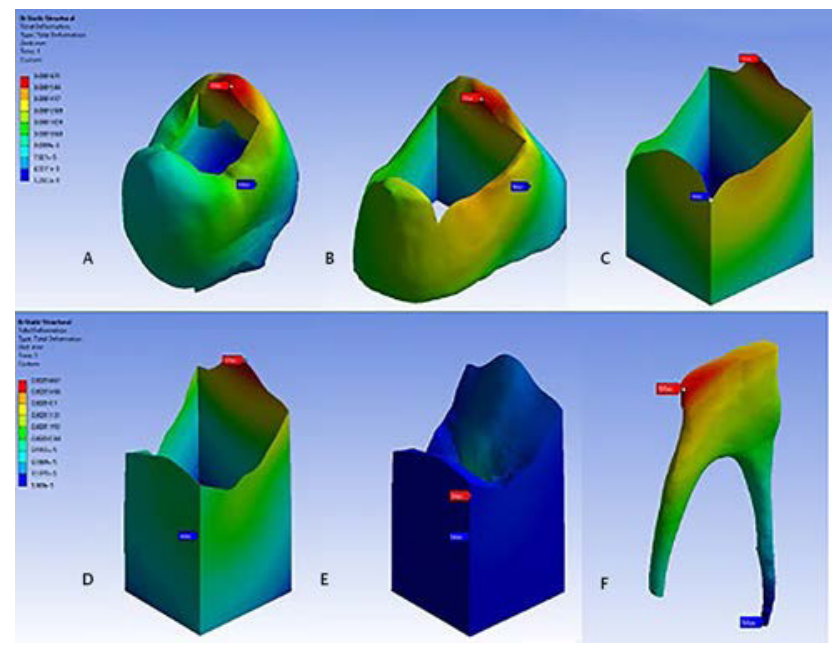

Fig. 2 Stress distribution from finite element analysis of threedimensional model 1 of each structure after receiving $50 \mathrm{~N}$ occlusal loading onto the composite resin. (A) enamel, (B) dentin, (C) hybrid layer, (D) adhesive layer, (E) composite resin, and (F) glass-ionomer cement.

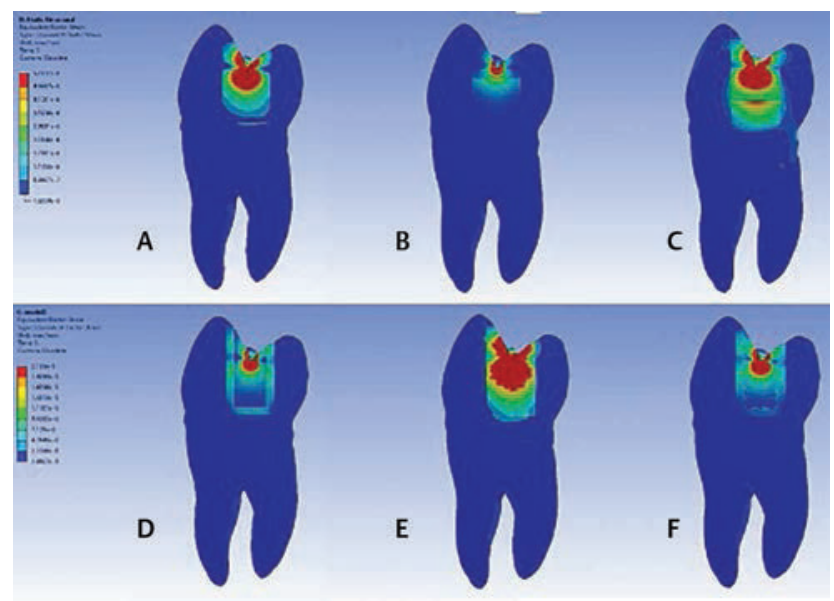

Fig. 3 Finite element analysis. (A) Model 1, (B) Model 2, (C) Model 3, (D) Model 4, (E) Model 5, (F), and Model 6.

with CT analyzer software (CTAn 1.16, Skyscan, Kontich, Belgium). $\mathrm{AgNO}_{3}$ represents microleakage as radiopaque in micro-CT images. These micro-CT images were used as controls before cyclic loading.

The specimens after micro-CT evaluation were further subjected to occlusal loading with $50 \mathrm{~N}$ force, 100,000 cycles, and $1.5 \mathrm{~Hz}$ frequency. Cyclic loading was performed under $100 \%$ humidity at the center of the restoration perpendicular to the tooth axis. Then, specimens were immersed in $50 \%$ ammoniacal $\mathrm{AgNO}_{3}$ solution for 24 hours as a tracer, which developed in X-ray developing solution for 15 minutes, fixed for 2 minutes, and subjected to microleakage evaluation with micro-CT. The microleakage data after cyclic loading were collected. The representative micro-CT images for microleakage analysis are presented in - Fig. $\mathbf{4}$. The red color areas demonstrate the microleakage.

\section{Statistical Analysis}

The means and standard deviations of volumetric microleakage were calculated. The Shapiro-Wilk test was used for analysis of the distribution of data. The homogeneity of variances was analyzed by Levene's test. The influences of the restorative materials and placement techniques and the cyclic loading were analyzed with two-way ANOVA. Then, statistical analysis of volumetric microleakage before and after cyclic loading was analyzed by using paired sample $t$-tests. In addition, the difference among restorative materials and placement techniques within the same condition of cyclic loading was analyzed with one-way ANOVA and Tukey's HSD multiple comparison at 95\% confidence intervals. SPSS version 18 (SPSS Inc., Chicago, Illinois, United States) was used for all statistical analyses.

\section{Results}

The maximum von Mises stresses when an occlusal force $(50 \mathrm{~N})$ was applied to the central groove are presented in - Table 3. Occlusal loading created stress in the composite in all models. The highest stress in the composite was found in Model 1, in which the cavity was restored with only Filtek Z250 (11.616 MPa). The lowest stress in the composite was found in Model 2, in which the bottom of the cavity was restored with Filtek Bulk Fill Flowable Restoration for $3 \mathrm{~mm}$ and covered occlusally with Filtek Z250 for $1 \mathrm{~mm}$ (5.8669 $\mathrm{MPa}$ ). The stress produced by occlusal loading for all models gradually decreased from high to low as follows: dentin, enamel, hybrid layer, and adhesive.

The use of a flowable restoration composite could reduce the stress from occlusal loading in the composite. Therefore, stress occurring in enamel and dentin was clearly increased, especially when the flowable was used as in Model 2 (0.17187 MPa)

The deformation $(\mathrm{mm})$ of each structure when an occlusal force $(50 \mathrm{~N})$ was applied to the central groove is presented in - Table 4. The maximum displacement was found in Model 6 , in which the cavity wall was lined with Filtek Bulk Fill Flowable Restoration and restored with Filtek Bulk Fill Posterior Restoration $(0.00165 \mathrm{~mm})$. The lowest amount of deformation was found in Model 3, in which the bottom of the cavity was restored with Filtek Bulk Fill Flowable Restoration for $1.5 \mathrm{~mm}$ and covered occlusally with Filtek Z250 for $2.5 \mathrm{~mm}$. The restoration with Filtek Bulk Fill Posterior Restoration (Groups 5 and 6) demonstrated a higher degree of

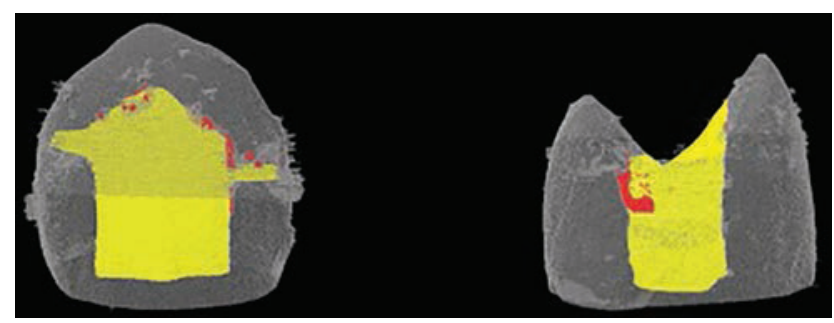

Fig. 4 Microcomputed tomography images for microleakage analysis. 
Table 2 Materials' details according to manufacturer's data

\begin{tabular}{|l|l|l|l|l|}
\hline Materials & Compositions & $\begin{array}{l}\text { Percent of filler } \\
\text { by volume }\end{array}$ & $\begin{array}{l}\text { Percent of filler } \\
\text { by weight }\end{array}$ & Manufacturer \\
\hline Filtek Z250 & $\begin{array}{l}\text { Resin matrix: Bis-GMA, TEGDMA, UDMA, } \\
\text { Bis-EMA } \\
\text { Filler: silica nanofillers, zirconia/silica } \\
\text { nanocluster }\end{array}$ & 60 & 78 & $\begin{array}{l}\text { 3M ESPE, St. } \\
\text { Paul, } \\
\text { Minnesota, } \\
\text { United States }\end{array}$ \\
\hline $\begin{array}{l}\text { Filtek Bulk Fill } \\
\text { Posterior } \\
\text { Restoration }\end{array}$ & $\begin{array}{l}\text { Resin matrix: Bis-GMA, UDMA, Bis-EMA, } \\
\text { AUDMA, AFM, DDDMA } \\
\text { Filler: silica nanofillers, zirconia/silica } \\
\text { nanocluster }\end{array}$ & 58.4 & 76.5 & $\begin{array}{l}3 \mathrm{M} \text { ESPE, St. } \\
\text { Paul, } \\
\text { Minnesota, } \\
\text { United States }\end{array}$ \\
\hline $\begin{array}{l}\text { Filtek Bulk Fill } \\
\text { Flowable } \\
\text { Restoration }\end{array}$ & $\begin{array}{l}\text { Resin matrix: Bis-GMA, TEGDMA, UDMA, } \\
\text { Bis-EMA, Bis-PMA } \\
\text { Filler: silica nanofillers, zirconia/silica } \\
\text { nanocluster }\end{array}$ & 64.5 & 42.5 & $\begin{array}{l}3 \mathrm{M} \text { ESPE, St. } \\
\text { Paul, } \\
\text { Minnesota, } \\
\text { United States }\end{array}$ \\
\hline $\begin{array}{l}\text { Single Bond } \\
\text { Universal Adhesive }\end{array}$ & $\begin{array}{l}\text { MDP phosphate monomer, } \\
\text { dimethacrylate resins, HEMA, modified } \\
\text { polyalkenoic acid copolymer, silane, filler, } \\
\text { ethanol, water }\end{array}$ & n/a & n/a & $\begin{array}{l}3 \mathrm{M} \text { ESPE, St. } \\
\text { Paul, } \\
\text { Minnesota, } \\
\text { United States }\end{array}$ \\
\hline $\begin{array}{l}\text { GC Fuji II LC } \\
\text { Capsule }\end{array}$ & $\begin{array}{l}\text { HEMA, Distilled water, Polyacrylic acid, } \\
\text { Powder: Fluoroaluminosilicate glass }\end{array}$ & & & $\begin{array}{l}\text { GC Corporation, } \\
\text { Tokyo, Japan }\end{array}$ \\
\hline
\end{tabular}

Abbreviations: AFM, addition fragmentation monomer; AUDMA, aromatic urethane dimethacrylate; Bis-EMA, ethoxylated bisphenol A dimethacrylate; Bis-GMA, bisphenol A diglycidyl methacrylate; DDDMA, dodecanediol dimethacrylate; HEMA, hydroxyethyl methacrylate; MDP, methacryloyloxydecyl dihydrogen phosphate; n/a, not available; TEGDMA, triethyl glycol dimethacrylate; UDMA, urethane dimethacrylate.

deformation when compared with the restoration with Filtek Z250 for both lining and no lining groups.

According to two-way ANOVA, significant effect of the restorative materials and placement techniques $(p<0.01)$ and the cyclic loading $(p<0.01)$ to volumetric microleakage were found with the interaction between two factors $(p<0.01)$. In addition, the power of test was investigated, which was 1.0. The effects of sample size were calculated that were 1.0 for the restorative materials and placement techniques, 1.0 for the cyclic loading and 0.99 for the interaction between two factors. The strong effect of sample size was found in this study.

The volumetric microleakage data for each group are shown in - Table 5. Only Group 6 (cavity lined with a 0.5mm-thick layer of Filtek Bulk Fill Flowable Restoration and restored with Filtek Bulk Fill Posterior) showed no significant difference in microleakage before and after cyclic loading. Group 5 (cavity restored with Filtek Bulk Fill Posterior) showed the lowest volumetric microleakage both before and after cyclic loading. The highest volumetric microleakage was observed in Group 1 (restored with Filtek Z250) both before and after cyclic loading.

Thus, the lowest volumetric microleakage observed in Group 5 was not significantly different from that in Group 2 (the bottom of the cavity was restored with Filtek Bulk Fill Flowable Restoration for $3 \mathrm{~mm}$ and covered occlusally with Filtek Z250 for $1 \mathrm{~mm}$ ); Group 3 (the bottom of the cavity was restored with Filtek Bulk Fill Flowable Restoration for $1.5 \mathrm{~mm}$ and covered occlusally with Filtek Z250 for $2.5 \mathrm{~mm}$ ); Group 4 (the cavity was lined with a $0.5-\mathrm{mm}$ thick layer of Filtek Bulk Fill Flowable Restoration and restored with Filtek Z250); and Group 6 (the cavity was lined with a $0.5-\mathrm{mm}$ thick layer of
Filtek Bulk Fill Flowable Restoration and restored with Filtek Bulk Fill Posterior Restoration) before cyclic loading conditions. No significant differences among Group 2, Group 4, and Group 6 were found after cyclic loading.

\section{Discussion}

After the establishment of models, different restorative techniques and restorative resin-based materials were used in this study. Occlusal force was loaded onto composite restorations to mimic the clinical situation. The finite element analysis was able to show the pattern of stress distribution and provide stress detail within each structure in Class I composite restorations. ${ }^{27}$ All models were simulations of a tooth-restoration system consisting of enamel, dentin, a hybrid layer, an adhesive layer, and resin composite. All components in the models were assumed to be isotropic, linearly elastic, and perfectly bounded together. Hence, the results for maximum Von Mises stress could not be interpreted by way of interfacial stress but only by stress consolidated in these models.

For this finite element analysis, six models were assigned to estimate the clinical use of bulk-fill composites compared with conventional hybrid composites (Filtek Z250). The bulkfill composites could be divided according to consistency into two types: regular consistency (Filtek Bulk Fill Posterior Restoration) and low consistency (Filtek Bulk Fill Flowable Restoration). These two types of bulk-fill composites have different clinical applications. The regular consistency type can be used as the usual posterior composite. Moreover, its low consistency requires the occlusal surface to be protected with a conventional composite because of its poor 
312 Effect of Occlusal Stress on Class I Composite Restoration Ritthiti et al.

Table 3 Maximum Von Mises stresses (MPa) by the effect of occlusal loading in each substrate

\begin{tabular}{|l|l|l|l|l|l|l|l|}
\hline Model & Enamel & Dentin & Hybrid layer & Adhesive & Flowable Co & Composite & Glass-ionomer cement \\
\hline Model 1 & 0.10040 & 0.10673 & 0.06208 & 0.00979 & & 11.616 & 0.01392 \\
\hline Model 2 & 0.17187 & 0.19882 & 0.06742 & 0.01779 & 0.22378 & 5.8669 & 0.01915 \\
\hline Model 3 & 0.12403 & 0.14739 & 0.05504 & 0.01054 & 0.02894 & 5.9837 & 0.01926 \\
\hline Model 4 & 0.10646 & 0.12683 & 0.04745 & 0.01056 & 0.01657 & 9.8271 & 0.02157 \\
\hline Model 5 & 0.12397 & 0.12989 & 0.05708 & 0.01210 & & 6.6683 & 0.01505 \\
\hline Model 6 & 0.12658 & 0.15244 & 0.05553 & 0.01090 & 0.13162 & 9.5324 & 0.01909 \\
\hline
\end{tabular}

mechanical properties. ${ }^{18,28,29}$ In addition, a flowable material was used as a cavity lining in the model in an attempt to reduce the effect of occlusal stress ${ }^{8}$ and improve adaptation. ${ }^{28,30}$ Thus, two types of bulk-fill composites with different clinical applications were employed in the models.

In Model 1, the cavity was restored with Filtek Z250 to a depth of $4 \mathrm{~mm}$ and was designed to simulate normal posterior composite restoration. In Model 4, the prepared surface of the cavity was lined with a $0.5-\mathrm{mm}$ thick layer of Filtek Bulk Fill Flowable Restoration, and the remaining cavity was restored with Filtek Z250 to simulate the use of a flowable composite as a stress absorbing layer in posterior restoration. ${ }^{8}$

In Model 2, the bottom of the cavity was restored with Filtek Bulk Fill Flowable Restoration for $3 \mathrm{~mm}$ and covered occlusally with Filtek Z250 for $1 \mathrm{~mm}$. In Model 3, the prepared surfaces of the cavity were lined with a $0.5-\mathrm{mm}$ thick layer of Filtek Bulk Fill Flowable Restoration, and the remaining cavity was restored with Filtek Z250. This configuration was used to simulate the clinical application of flowable bulk-fill composites with different thicknesses according to the manufacturer's recommendation. ${ }^{18-20}$

The application of bulk-fill composite resin with its regular consistency was used in Model 5 and Model 6. Model 5: the cavity restored with Filtek Bulk Fill Posterior Restoration for $4 \mathrm{~mm}$ depth was designed to simulate normal use of the bulk-fill composite. In addition, the flowable lining was applied to Model 6 to improve clinical adaptation. ${ }^{28}$

The highest maximum Von Mises stress was found in Model 1 on the Filtek Z250 composite resin. The occlusal stress on Filtek Z250 could decrease with the application of low viscosity resin (flowable composite) underneath the hybrid composite resin (Model 2 and Model 3) and with the application of a flowable material as the lining (Model 4).
The result was in agreement with that of a previous study. ${ }^{8}$ The use of bulk-fill composite with regular consistency as a restorative material (Model 5 and Model 6) could reduce occlusal stress on the composite when compared with the models restored with Filtek Z250. The lower modulus of elasticity of the bulk-fill composite compared with the conventional hybrid composite (-Table 1) may affect the absorption and distribution of stress. ${ }^{8,31}$ Since comparable mechanical properties of bulk-fill composites to conventional composites have been reported, ${ }^{32}$ this may ensure the effective use of bulk-fill composites for posterior restoration. ${ }^{29}$

The six models in finite element analysis were employed for the in vitro microleakage test of this study. Micro-CT was used to evaluate the microleakage with the use of a silver nitrate solution as a tracer. ${ }^{33}$ The advantage of micro-CT is that it allows the volumetric leakage from the constructed three-dimensional model to be evaluated with a noninvasive process.

Various degrees of leakage were found in all groups and leakage was affected by cyclic loading of $50 \mathrm{~N}$ force with 100,000 cycles in this study. The use of universal adhesive with a self-etching mode onto enamel might have low efficiency for bonding with enamel because of self-etching mode was less effective, and lead to microleakage for all specimens. ${ }^{34}$ To simulate 2 months of chewing, 100,000 cycles of cyclic loading were used. ${ }^{35}$ Cyclic loading might initiate mechanical degradation, resulting in an increase in microleakage after cyclic loading in this study. ${ }^{36}$ The leakage occurring before cyclic loading might act as a crack initiator. After progressive cyclic loading, microleakage might result from crack propagation. ${ }^{37}$

In addition, without the cyclic loading, the microleakage was also found. The volumetric shrinkage of restorative

Table 4 Deformation $(\mathrm{mm})$ by the effect of occlusal loading in each substrate

\begin{tabular}{|l|l|l|l|l|l|l|l|}
\hline Groups & Enamel & Dentin & Hybrid layer & Adhesive & Flowable Co & Composite & Glass-ionomer cement \\
\hline Model 1 & 0.00016 & 0.00013 & 0.00013 & 0.00016 & & 0.00084 & 0.00007 \\
\hline Model 2 & 0.00020 & 0.00015 & 0.00015 & 0.00020 & 0.00029 & 0.00087 & 0.00007 \\
\hline Model 3 & 0.00016 & 0.00012 & 0.00013 & 0.00016 & 0.00011 & 0.00078 & 0.00007 \\
\hline Model 4 & 0.00019 & 0.00014 & 0.00014 & 0.00019 & 0.00020 & 0.00102 & 0.00007 \\
\hline Model 5 & 0.00021 & 0.00016 & 0.00016 & 0.00021 & & 0.00134 & 0.00008 \\
\hline Model 6 & 0.00024 & 0.00018 & 0.00018 & 0.00024 & 0.00024 & 0.00165 & 0.00009 \\
\hline
\end{tabular}


Table 5 Means and standard deviations of volumetric microleakage

\begin{tabular}{|l|l|l|}
\hline \multirow{2}{*}{ Groups } & \multicolumn{2}{|l|}{ Microleakage $\left(\mathrm{mm}^{3}\right)$} \\
\cline { 2 - 3 } & Before cyclic loading & After cyclic loading \\
\hline Group 1 & $0.038 \pm 0.012^{\mathrm{aB}}$ & $0.096 \pm 0.007^{\mathrm{bD}}$ \\
\hline Group 2 & $0.015 \pm 0.003^{\mathrm{aA}}$ & $0.045 \pm 0.007^{\mathrm{bBC}}$ \\
\hline Group 3 & $0.023 \pm 0.013^{\mathrm{aAB}}$ & $0.057 \pm 0.006^{\mathrm{bC}}$ \\
\hline Group 4 & $0.014 \pm 0.011^{\mathrm{aA}}$ & $0.032 \pm 0.110^{\mathrm{bAB}}$ \\
\hline Group 5 & $0.014 \pm 0.004^{\mathrm{aA}}$ & $0.029 \pm 0.008^{\mathrm{bA}}$ \\
\hline Group 6 & $0.031 \pm 0.015^{\mathrm{aAB}}$ & $0.045 \pm 0.010^{\mathrm{aBC}}$ \\
\hline
\end{tabular}

Note: Data with different uppercase letters in columns and lowercase letters in rows indicate significant differences $(p \leq 0.05)$.

materials may contribute for this observation. According to previous studies, the volumetric shrinkage of Z250, Filtek Bulk Fill Posterior Restoration and Filtek Bulk Fill Flowable Restoration were approximately $1.9,1.1$, and $1.4 \%{ }^{38,39}$ The relatively high volumetric shrinkage in combination with high modulus of elasticity of Z250 might cause high shrinkage stress that affected high volumetric leakage found in Group $1 .^{14,40}$

The null hypothesis of this study was rejected. After cyclic loading, the capability of the flowable lining to reduce microleakage was found (Group 4 and Group 6). Therefore, the leakage of Group 4 was not significantly different from Group 5, in which the cavities were restored with bulk-fill composite. This might indicate that the greatest effectiveness is achieved when lining with a flowable material when a high modulus composite was used. This was comparable to the restoration by using only bulk-fill composite. The effective use of bulk-fill composites to reduce microleakage should be evident from their low polymerization shrinkage and relatively low elastic moduli that could reduce the stress effect, ${ }^{14,38}$ resulting in low microleakage in this study.

Since this study performed in class I cavity with only enamel margin, the application to the cavity with dentin margin as found in class II should be concerned. The higher microleakage at dentin margin than at enamel margin has been reported. ${ }^{41}$

\section{Conclusion}

Within the limitations of this study, the use of low viscosity composite resin (flowable composite as a cavity lining or restoration underneath the conventional composite) can reduce the occlusal stress loading onto composite resin based on finite element analysis. The cyclic occlusal stress on the composite increased microleakage in Class I composite restorations. The most effective cavity lining with a flowable composite was found when this lining was used with a high elastic modulus composite resin.

\section{Funding}

This study was supported by the Faculty of Dentistry, Mahidol University.
Conflict of Interest

None declared.

\section{References}

1 Qvist V, Qvist J, Mjör IA. Placement and longevity of tooth-colored restorations in Denmark. Acta Odontol Scand 1990;48(05): 305-311

2 Mjör IA, Toffenetti F. Placement and replacement of resinbased composite restorations in Italy. Oper Dent 1992;17 (03):82-85

3 Nedeljkovic I, De Munck J, Vanloy A, et al. Secondary caries: prevalence, characteristics, and approach. Clin Oral Investig 2020;24(02):683-691

4 Papadogiannis Y, Lakes RS, Palaghias G, Helvatjoglu-Antoniades M, Papadogiannis D. Fatigue of packable dental composites. Dent Mater 2007;23(02):235-242

5 Reid LC, Kazemi RB, Meiers JC. Effect of fatigue testing on core integrity and post microleakage of teeth restored with different post systems. J Endod 2003;29(02):125-131

6 Arisu HD, Uçtasli MB, Eligüzeloglu E, Ozcan S, Omürlü H The effect of occlusal loading on the microleakage of class $\mathrm{V}$ restorations. Oper Dent 2008;33(02):135-141

7 Belli R, Geinzer E, Muschweck A, Petschelt A, Lohbauer U. Mechanical fatigue degradation of ceramics versus resin composites for dental restorations. Dent Mater 2014;30(04): 424-432

8 Anatavara S, Sitthiseripratip K, Senawongse P. Stress relieving behaviour of flowable composite liners: a finite element analysis. Dent Mater J 2016;35(03):369-378

9 Soappman MJ, Nazari A, Porter JA, Arola D. A comparison of fatigue crack growth in resin composite, dentin and the interface. Dent Mater 2007;23(05):608-614

10 Farzin M, Bahrani F, Nejebat N, Meshki R. The fatigue behavior of restorations used under the rest of removable partial denture. J Dent Biomater 2014;1:32-36

11 Flury S, Peutzfeldt A, Lussi A. Influence of increment thickness on microhardness and dentin bond strength of bulk fill resin composites. Dent Mater 2014;30(10):1104-1112

12 Czasch P, Ilie N. In vitro comparison of mechanical properties and degree of cure of bulk fill composites. Clin Oral Investig 2013; 17(01):227-235

13 Alrahlah A, Silikas N, Watts DC. Post-cure depth of cure of bulk fill dental resin-composites. Dent Mater 2014;30(02): 149-154

14 El-Damanhoury H, Platt J. Polymerization shrinkage stress kinetics and related properties of bulk-fill resin composites. Oper Dent 2014;39(04):374-382

15 Moorthy A, Hogg $\mathrm{CH}$, Dowling AH, Grufferty BF, Benetti AR, Fleming GJ. Cuspal deflection and microleakage in premolar teeth restored with bulk-fill flowable resin-based composite base materials. J Dent 2012;40(06):500-505

16 Leprince JG, Palin WM, Vanacker J, Sabbagh J, Devaux J, Leloup G. Physico-mechanical characteristics of commercially available bulk-fill composites. J Dent 2014;42(08):993-1000

17 Baroudi K, Rodrigues JC. Flowable resin composites: a systematic review and clinical considerations. J Clin Diagn Res 2015;9(06): ZE18-ZE24

18 Product specification for Filtek Bulk Fill Flowable Restorative (3M ESPE, St.Paul, MN, USA). Accessed 2021 at: https://multimedia.3m.com/mws/media/7923210/filtek-bulk-fill-flowable-restorative-technical-product-profile.pdf

19 Product specification for SDR (Dentsply Caulk, Milford, DE, USA). Accessed 2021 at: https://assets.dentsplysirona.com/dentsply/ $\mathrm{pim} /$ manufacturer/Restorative/Direct_Restoration/CompositeS_Flowables/Flowables/SDR_flow/SDR\%20flow\%2B_DFU_EN_DE_IT_FR_ES.pdf 
20 Product specification for x-tra base (Voco GmbH, Cuxhaven, Germany). Accessed 2021 at: https://www.voco.dental/us/ portaldata/1/resources/products/instructions-for-use/us/Xtra-base_ifu_us.pdf

21 Habelitz S, Marshall SJ, Marshall GW Jr, Balooch M. Mechanical properties of human dental enamel on the nanometre scale. Arch Oral Biol 2001;46(02):173-183

22 Pongprueksa P, Kuphasuk W, Senawongse P. The elastic moduli across various types of resin/dentin interfaces. Dent Mater 2008; 24(08):1102-1106

23 Zhu J, Rong Q, Wang X, Gao X. Influence of remaining tooth structure and restorative material type on stress distribution in endodontically treated maxillary premolars: A finite element analysis. J Prosthet Dent 2017;117(05):646-655

24 Pongprueksa P, De Munck J, Karunratanakul K, et al. Dentin bonding testing using a mini-interfacial fracture toughness approach. J Dent Res 2016;95(03):327-333

25 Rosentritt M, Behr M, van der Zel JM, Feilzer AJ. Approach for valuating the influence of laboratory simulation. Dent Mater 2009;25(03):348-352

26 Perillo L, Sorrentino R, Apicella D, et al. Nonlinear visco-elastic finite element analysis of porcelain veneers: a submodelling approach to strain and stress distributions in adhesive and resin cement. J Adhes Dent 2010;12(05):403-413

27 Versluis A, Tantbirojn D, Pintado MR, DeLong R, Douglas WH. Residual shrinkage stress distributions in molars after composite restoration. Dent Mater 2004;20(06):554-564

28 Van Ende A, De Munck J, Lise DP, Van Meerbeek B. Bulk-fill composites: a review of the current literature. J Adhes Dent 2017;19(02):95-109

29 Chesterman J, Jowett A, Gallacher A, Nixon P. Bulk-fill resin-based composite restorative materials: a review. Br Dent J 2017;222 (05):337-344

30 Yoshimine N, Shimada Y, Tagami J, Sadr A. Interfacial adaptation of composite restorations before and after light curing: effects of adhesive and filling technique. J Adhes Dent 2015;17(04): 329-336
31 Van Meerbeek B, Willems G, Celis JP, et al. Assessment by nanoindentation of the hardness and elasticity of the resin-dentin bonding area. J Dent Res 1993;72(10):1434-1442

32 Vidhawan SA, Yap AU, Ornaghi BP, et al. Fatigue stipulation of bulk-fill composites: an in vitro appraisal. Dent Mater 2015;31 (09):1068-1074

33 Eden E, Topaloglu-Ak A, Cuijpers V, Frencken JE. Micro-CT for measuring marginal leakage of Class II resin composite restorations in primary molars prepared in vivo. Am J Dent 2008;21(06): 393-397

34 Rosa WL, Piva E, Silva AF. Bond strength of universal adhesives: a systematic review and meta-analysis. J Dent 2015;43(07):765-776

35 Ruse ND, Shew R, Feduik D. In vitro fatigue testing of a dental bonding system on enamel. J Biomed Mater Res 1995;29(03): 411-415

36 Lohbauer U, Belli R, Ferracane JL. Factors involved in mechanical fatigue degradation of dental composite restorations. J Dent Res 2013;92(07):584-591

37 Shah MB, Ferracane JL, Kruzic JJ. Mechanistic aspects of fatigue crack growth behavior in resin based dental restorative composites. Dent Mater 2009;25(07):909-916

38 Nagem Filho H, Nagem HD, Francisconi PA, Franco EB, Mondelli RF, Coutinho KQ. Volumetric polymerization shrinkage of contemporary composite resins. J Appl Oral Sci 2007;15(05):448-452

39 Gonçalves F, Campos LMP, Rodrigues-Júnior EC, AGonçalves F, Campos LMP, Rodrigues-Júnior EC, Costa FV, Marques PA, Francci CE, Braga RR, Boaro LCC. A comparative study of bulk-fill composites: degree of conversion, post-gel shrinkage and cytotoxicity. Braz Oral Res 2018;8(32):e17. Doi: 10.1590/18073107bor-2018.vol32.0017

40 Kim RJ, Kim YJ, Choi NS, Lee IB. Polymerization shrinkage, modulus, and shrinkage stress related to tooth-restoration interfacial debonding in bulk-fill composites. J Dent 2015;43(04):430-439

41 Mohamed NI, Safy RK, Elezz AF. Microtensile bond strength, marginal leakage, and antibacterial effect of bulk fill resin composite with alkaline fillers versus incremental nanohybrid composite resin. Eur J Dent 2021;15(03):425-432 